\title{
Experimental Study on Strength Influencing Factors of Calcareous Nodule Soil in Northern Jiangsu
}

\author{
Xiaolong $\mathrm{WANG}^{\mathrm{a}}$, Jianling GU ${ }^{\mathrm{b}, 1}$, Song $\mathrm{XU}^{\mathrm{a}}$ and Shengdong $\mathrm{GU}^{\mathrm{c}}$ \\ ${ }^{a}$ China Energy Engineering Group Jiangsu Power Design Institute Co., Ltd., Nanjing \\ 210005, China \\ ${ }^{\mathrm{b}}$ Key Laboratory of Ministry of Education for Geomechanics and Embankment \\ Engineering, Hohai University, Nanjing, 210098, China \\ c Unit 92301 of the Chinese People's Liberation Army, Beijing, 100841, China
}

\begin{abstract}
The physical and mechanical properties of calcareous concretion soil depend largely on the shape, size and distribution of calcareous concretion soil besides the impact of soil layer. Due to the long time required for clay saturation, consolidation, and shearing, as well as the tedious sample preparation, larger triaxial tests of calcareous nodules have not been carried out. In this chapter, based on the medium triaxial test of calcareous nodules, the strength characteristics of remolded soil samples under different confining pressures are studied. By controlling parameters such as calcareous nodules particle size and water content, the impact of different test conditions on the strength of calcareous nodules is analysed, and the variation rule is analysed. It is concluded that the impact of nodular particle size on soil strength is not obvious at $20 \%$ nodular content. The impact of different water content on the strength of soil is more regular, showing hardening characteristics, in line with the natural law.
\end{abstract}

Keywords. Calcareous nodule soil, particle size, water content, triaxial test

\section{Introduction}

Calcareous nodule soil is a sort of regional special soil with $\mathrm{CaCO}_{3}$ content of more than 50\%, which is mainly distributed in Huaibei Plain of Anhui Province and northern Jiangsu Province of China. Calcareous nodules are composed of fine-grained clay and coarse-grained calcareous nodules. It is a typical two-phase granular-grained soil. The physical and mechanical properties of calcareous nodules depend largely on the shape, size and distribution of calcareous nodules in addition to the influence of soil layer, which is very uneven. Cao Yajuan pointed out that calcareous nodules all had obvious edges and corners, and were arranged in the soil layer in a disorderly manner, like ginger. Wu Daoxiang [1] defined the characteristic fine-grained (clay, silt) -coarsegrained (calcareous concretion) structure of calcareous concretion. Wang Guoqiang [2] proposed that calcareous concretion soil has significant structural and heterogeneous characteristics, and gave an empirical formula for the carrying capacity of calcareous

\footnotetext{
1 Jianling Gu, Key Laboratory of Ministry of Education for Geomechanics and Embankment Engineering, Hohai University, Nanjing, 210098, China; E-mail: 1574281015@qq.com.
} 
concretion soil foundation. Wu Daoxiang [3] also pointed out that the distribution, shape and particle size of calcareous concretions in Huaibei Plain, Anhui Province are very uneven. Calcareous concretions are dense and hard, so the subsistent of calcareous concretions makes the soil show inhomogeneity and anisotropy. Huang Xinghuai and Wu Zhihai [4] took the calcareous nodules clay from a power plant in the Huaibei Plain as the research object. Due to the removal of calcareous nodules in the soil, the physical and mechanical indexes obtained by indoor geotechnical tests show great range and large coefficient of variation. It can be seen that the existence of calcareous nodules makes the laboratory test data more discrete and less reliable. Lan Tianpeng [5] conducted a large-scale direct shear test using the original and refolded calcareous nodular soil samples. Xiong Yonghua and Hu Bo [6] studied the effects of calcareous concretion content and water content on the strength of calcareous concretion soil in Xinjiang by direct shear test.

\section{Test Programme Design}

According to the "Coarse-grained Soil Test Rules for Hydraulic and Hydropower Engineering", the diameter of the sample is greater than or equal to the maximum particle size of the sample. The diameter of the middle triaxial sample is $101 \mathrm{~mm}$. According to the calculation of the specification, the peak value particle size of the sample is $20 \mathrm{~mm}$, while the maximum particle size of the calcareous nodules in the calcareous nodules soil is more than $40 \mathrm{~mm}$, far exceeding the maximum particle size allowed in the specification. So, the calcareous nodules in the sample should be scaled down to a certain extent. In this paper, the equivalent substitution method was used to scale calcareous nodules (according to the content of each particle group below the allowable maximum particle size of the sample and larger than $5 \mathrm{~mm}$, super particle size particles were replaced according to the proportion and equal mass). The specific calculation formula is as follows:

$$
P_{i}=\frac{P_{5}}{P_{5}-P_{d \max }} P_{0 i}
$$

In the formula:

$\mathrm{P}_{\mathrm{i}}--$ content of a granule group after substitution, $\%$;

$\mathrm{P}_{5}$-- content of granule group with original gradation greater than $5 \mathrm{~mm}, \%$;

Gradation after scaling is shown in table 1 . According to the physical indexes of the original soil sample, the dry density of refolded soil sample is $\rho_{d}=1.63 \mathrm{~g} / \mathrm{cm}^{3}$.

Table 1. Particle content of soil material in triaxial test with different water content.

\begin{tabular}{lcccccccc}
\hline Particle size $(\mathrm{mm})$ & $>40$ & $40 \sim 20$ & $20 \sim 10$ & $10 \sim 5$ & $5 \sim 2$ & $2 \sim 1$ & $1 \sim 0.5$ & $0.5 \sim 0.25$ \\
\hline $\begin{array}{l}\text { Raw material } \\
\text { Gradation (\%) }\end{array}$ & 3.52 & 10.48 & 11.78 & 21.96 & 22.81 & 14.69 & 8.68 & 6.07 \\
$\begin{array}{l}\text { Alternative } \\
\text { material gradation }(\%)\end{array}$ & 0 & 13.70 & 25.54 & 26.52 & 17.08 & 10.09 & 7.06 \\
\hline
\end{tabular}


Due to the large size of the sample in the middle triaxial test, it is difficult to obtain the original soil sample, so the test samples in this chapter are all refolded soil samples. In order to guarantee the veracity of the test, the soil material obtained from Suqian area was tested by particle separation. Water content and particle size of calcareous nodules were used as variables to prepare remolded soil samples. In the triaxial test with water content as the variable, the water content is $10 \%, 25 \%$ and $30 \%$ respectively. In the middle triaxial test with the particle size of calcareous concretions as a variable, three groups of soil samples with particle size of calcareous concretions of $2 \sim 5 \mathrm{~mm}$, $5 \sim 10 \mathrm{~mm}$ and 10 20mm were numbered as group 1, group 2 and group 3 respectively. The corresponding masses are shown in table 2.

Table 2. Soil content in triaxial tests with different sizes of calcareous nodules.

\begin{tabular}{llll}
\hline $\begin{array}{l}\text { Group } \\
\text { number }\end{array}$ & $\begin{array}{l}\text { Dry density } \\
\left(\mathrm{g} / \mathrm{cm}^{-3}\right)\end{array}$ & $\begin{array}{l}\text { Calcareous tuberculous } \\
\text { mass }(\mathrm{g})\end{array}$ & $\begin{array}{l}\text { Particle size is less than 2mm } \\
\text { particle mass }(\mathrm{g})\end{array}$ \\
\hline 1 & 1.662 & 223.1 & 2437.7 \\
2 & 1.661 & 222.1 & 2438.2 \\
3 & 1.662 & 225.0 & 2436.0 \\
\hline
\end{tabular}

\section{Analysis of the Elements Affecting the Strength of Calcareous Nodules}

\subsection{Influence of Particle Size}

To research the impact of nodular particle size on the strength of calcareous nodular soil, three groups with different particle size of $2-5 \mathrm{~mm}, 5-10 \mathrm{~mm}$ and $10-20 \mathrm{~mm}$ were selected for the middle triaxial $\mathrm{CD}$ test. The confining pressures were $50 \mathrm{kPa}, 100 \mathrm{kPa}$, $150 \mathrm{kPa}$ and $200 \mathrm{kPa}$ respectively. The content of calcareous nodular soil was $20 \%$. See figure 1 for the curve obtained from the test.

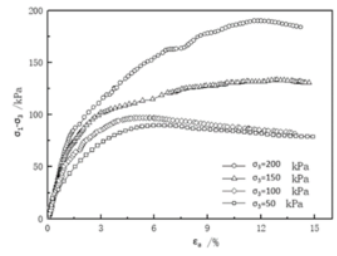

(a) particle size $2-5 \mathrm{~mm}$

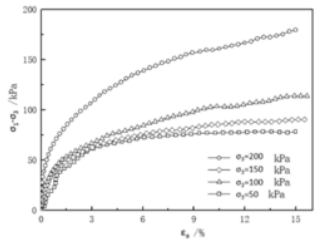

(b) particle size $5-10 \mathrm{~mm}$

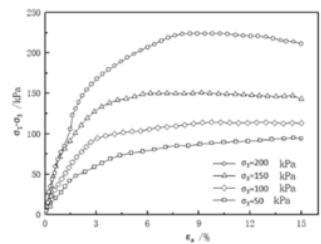

(c) particle size 10-20mm

Figure 1. $\left(\sigma_{1}-\sigma_{3}\right) \sim \varepsilon_{a}$ curve of calcareous nodules with different particle sizes.

It can be seen from the above curves that the stress-strain curve of the specimen is generally smooth, and the principal stress difference has a small fluctuation locally. In the process of shearing, with the increase of the principal stress difference, there will be a failure surface in the weak plane where the shear stress concentration is concentrated. Due to the great difference between the particle size of fine particles and calcareous nodules, the plane of rupture often passes through the location of calcareous nodules. During the shear process, the movement of calcareous nodules is easy to cause fluctuations on the curve of test results. 
The stress-strain curves of the samples are generally hardening and softening under some low confining pressures. In the shear process, the axial strain increases with the increase of principal stress difference. When it reaches a certain value, the curve will have a peak stress, which is the failure strength, and then the strength begins to decrease and gradually becomes stable. The failure strength of the sample increases gradually with the increase of confining pressure. This is because at low confining pressure, the resistance to particle movement is small, and the stress can reach the maximum at low strain, which is softening type on the stress-strain curve. When the confining pressure is large, the particles in the sample are closely arranged and have a greater strength. At the beginning shear stage, the shear stress is small, and the principal stress difference is large under a small axial displacement, and the stressstrain curve is nearly linear. After that, as the stress continues to increase, the calcareous nodules produce a large stress concentration, and the failure surface gradually forms, and the stress increases slowly until the sample is destroyed.

Table 3 lists the shear strength and principal stress ratio of calcareous nodular soil under three different particle size ranges. As shown from the table that the shear strength of the sample increases with the increase of the confining pressure, while the principal stress ratio changes little with the confining pressure and basically remains unchanged. The reason may be that the calcareous concretion content of the sample is small, and the calcareous concretion is difficult to contact with each other in the shear process, and cannot play the role of skeleton, and the corresponding stress is mainly borne by fine particles in the shear process. However, because the particle size difference of fine particles is not obvious and the movement resistance between particles is large, the shear strength of soil does not change significantly, so the failure principal stress ratio basically remains unchanged.

Table 3. Triaxial shear strength and failure principal stress ratio in different nodular particle sizes.

\begin{tabular}{|c|c|c|c|c|c|c|c|c|}
\hline \multirow{2}{*}{$\begin{array}{l}\text { Particle } \\
\text { size }(\mathrm{mm})\end{array}$} & \multicolumn{4}{|c|}{$\tau(\mathrm{kPa})$} & \multicolumn{4}{|c|}{$\sigma_{1} / \sigma_{3}$} \\
\hline & $50 \mathrm{kPa}$ & $100 \mathrm{kPa}$ & $150 \mathrm{kPa}$ & $200 \mathrm{kPa}$ & $50 \mathrm{kPa}$ & $100 \mathrm{kPa}$ & $150 \mathrm{kPa}$ & $200 \mathrm{kPa}$ \\
\hline $2-5$ & 89.10 & 97.11 & 133.06 & 190.40 & 2.78 & 1.97 & 1.89 & 1.95 \\
\hline $5-10$ & 78.20 & 90.41 & 113.72 & 179.26 & 1.88 & 1.93 & 1.85 & 1.94 \\
\hline $10-20$ & 94.73 & 114.21 & 150.72 & 224.15 & 2.21 & 2.26 & 2.33 & 2.25 \\
\hline
\end{tabular}

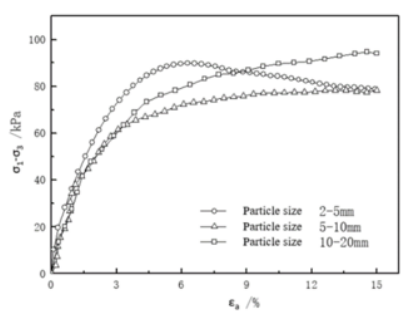

(a) confining pressure $50 \mathrm{kPa}$.

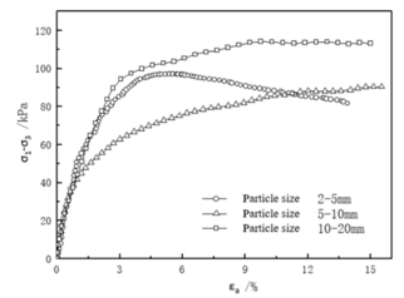

(b) confining pressure $100 \mathrm{kPa}$. 


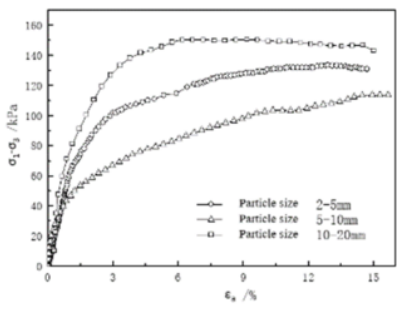

(c) confining pressure $150 \mathrm{kPa}$.

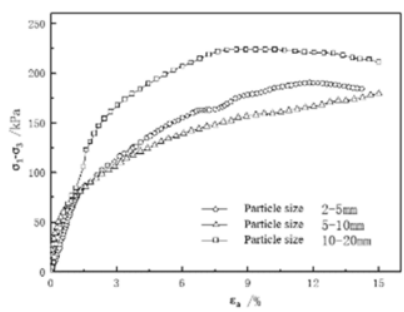

(d) confining pressure $200 \mathrm{kPa}$.

Figure 2. $\left(\sigma_{1}-\sigma_{3}\right) \sim \varepsilon_{a}$ curves of different particle sizes under the same confining pressure.

To show the impact of the nodular particle size as much as possible, the curves of samples with confining pressures of $50 \mathrm{kPa}, 100 \mathrm{kPa}, 150 \mathrm{kPa}$ and $200 \mathrm{kPa}$ are respectively made. As can be seen from figure 2, the maximum principal stress difference of $10-20 \mathrm{~mm}$ particle size sample is larger under the same confining pressure. The confining pressure value is $50 \mathrm{kPa}$, the strength of $10-20 \mathrm{~mm}$ particle size is lower than that of $2-5 \mathrm{~mm}$ particle size sample. However, the difference of principal stress of the samples with particle size of $2-5 \mathrm{~mm}$ and $5-10 \mathrm{~mm}$ is not obvious. In order to better reveal the strength characteristics of the sample, the Coulomb strength theory was used to draw the Mohr Circle and the strength envelope, and the corresponding cohesion and internal friction Angle were calculated, and the curve shown in figure 3 is obtained.

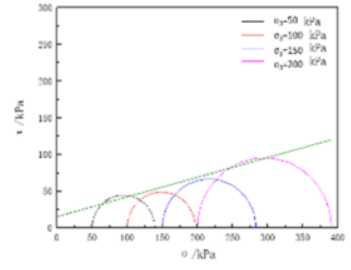

(a) particle size $2-5 \mathrm{~mm}$.

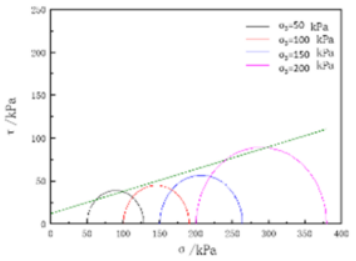

(b) particle size $5-10 \mathrm{~mm}$.

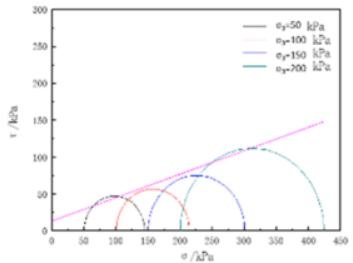

(c) particle size $10-20 \mathrm{~mm}$.

Figure 3. Mohr circle and strength envelope of calcareous concretion with different particle sizes.

Table 4. Strength index of samples with different calcareous concretion size.

\begin{tabular}{llll}
\hline \multirow{2}{*}{ Intensity } & \multicolumn{3}{l}{ Calcareous concretion size range $(\mathrm{mm})$} \\
\cline { 2 - 4 } & $2-5$ & $5-10$ & $10-20$ \\
$c(\mathrm{KPa})$ & 15.40 & 17.65 & 14.63 \\
$\varphi\left({ }^{\circ}\right)$ & 14.99 & 12.00 & 13.60 \\
\hline
\end{tabular}

The data obtained from the curves in figure 3 were sorted into table 4 , TB size for 10-20 $\mathrm{mm}$ sample intensity index is low, the reason may be more size larger TB suspended in fine particles, due to the size difference between the TB and fine particle is larger, when under shear, TB and fine-grained interface is more prone to stress concentration, TB and elastic mismatch between fine particles, interface crack. With the increase of shear force, the crack area gradually expands, forming a failure surface, and finally the soil will be damaged. 


\subsection{Influence of Water Content}

Mid-triaxial tests were researched on calcareous concretion soil samples with water content of $10 \%, 25 \%$ and $30 \%$, and confining pressures of $50 \mathrm{kPa}, 100 \mathrm{kPa}$ and $200 \mathrm{kPa}$ respectively.

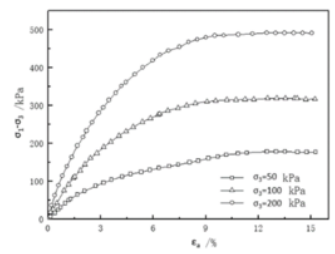

(a) $10 \%$ water content.

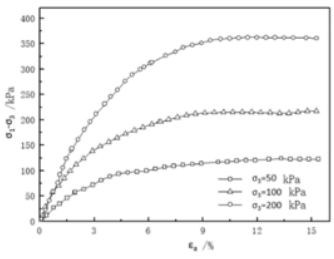

(b) $25 \%$ water content.

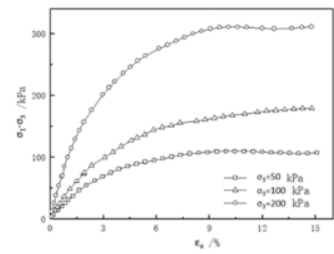

(c) $30 \%$ water content.

Figure 4. $\left(\sigma_{1}-\sigma_{3}\right) \sim \varepsilon_{a}$ curves of samples with different water content.

As shown in figure 4, under the same water content, the stress-strain curves of the samples all show obvious hardening phenomenon. When the shear force exceeds a certain value, the relative displacement between the calcareous concretion gradually stops, the strength of the samples gradually stabilizes, and the strength increases slowly.

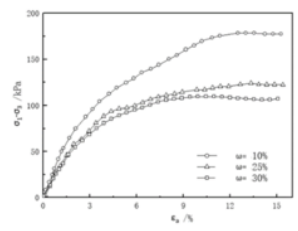

(a) confining pressure $50 \mathrm{kPa}$.

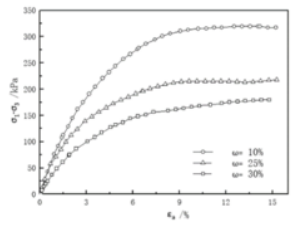

(b) confining pressure $100 \mathrm{kPa}$.

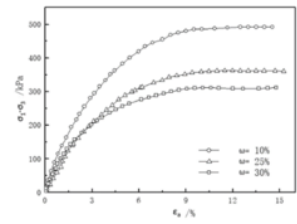

(c) confining pressure $200 \mathrm{kPa}$.

Figure 5. $\left(\sigma_{1}-\sigma_{3}\right) \sim \varepsilon_{a}$ curves of samples with different water content under the same confining pressure.

This is shown in figure 5, under the same confining pressure, with the increase of water content, the principal stress difference decreases gradually, the axial strain $\varepsilon_{a f}$ corresponding to the peak deviatoric stress of the sample decreases gradually, and the fine granular soil gradually changes from a hard state to a plastic state. In the shear process, the fine grain soil cannot fix the calcareous nodules, and the nodules are easy to slide in the soil, which reduces the influence on the strength of the soil and reduces the strength of the sample.

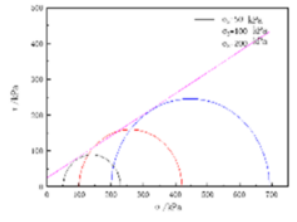

(a) $10 \%$ water content.

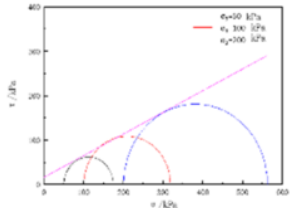

(b) $25 \%$ water content.

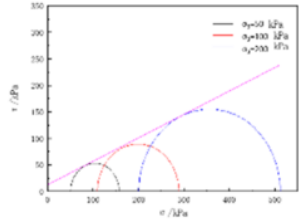

(c) $30 \%$ water content.

Figure 6. Mohr circle and shear strength envelope at different confining pressures under the same water content. 
Table 5. Strength index of samples with different water content.

\begin{tabular}{llll}
\hline \multirow{2}{*}{ Intensity } & Water content & \\
\cline { 2 - 3 } & $10 \%$ & $25 \%$ & $30 \%$ \\
$\mathrm{c}(\mathrm{kPa})$ & 25.54 & 16.10 & 13.42 \\
$\varphi_{\left({ }^{\circ}\right)}$ & 30.46 & 26.09 & 23.83 \\
\hline
\end{tabular}

As shown in figure 6 and table 5, with the increase of water content, $c$ and $\varphi$ decrease gradually. When the water content increases, the free water content between particles increases, and the fine particles change from the hard state to the plastic state, and the water between the calcareous concretion plays a lubrication role, so that the bite force between the calcareous concretion decreases, and the $\varphi$ of the samples decreases.

\section{Conclusions}

(1) The $\left(\sigma_{1}-\sigma_{3}\right) \sim \varepsilon_{a}$ curves of calcareous concretion with different particle sizes generally showed hardening characteristics. When the particle size of calcareous concretion reaches $10-20 \mathrm{~mm}$, the strength index of calcareous concretion decreases with the increase of particle size.

(2) The $\left(\sigma_{1}-\sigma_{3}\right) \sim \varepsilon_{a}$ curves of samples with different water content show obvious hardening characteristics. When the water content increases, the axial strain $\varepsilon_{a f}$ corresponding to the peak deviatoric stress decreases gradually. $c$ and $\varphi$ of soil decreased with the increase of water content.

(3) When the nodule content is $20 \%$, the impact of nodule particle size on the soil strength is not obvious, because at this content, the calcareous concretion is suspended in the soil and does not play the role of skeleton. However, in the studies with different water content, the concretion content in the samples after scaling is about $60 \%$, and the impact of water content on soil strength is more regular.

\section{References}

[1] Wu DX, Cao YJ, Zhong XM, Shi GJ, Xu DS, Liu QY, Wang GQ. Distribution and genetic age of calcareous nodular soil in Huaibei Plain, Anhui Province. Rock and Soil Mechanics. 2009 Dec; 30(S2): 434-439.

[2] Wang GQ, Wu DX, Yue T, Chen TH, Jiang KN, Zhao HH. Determination of properties and bearing capacity of newly deposited silt in Bo Zhou City, Anhui Province. Geology and Exploration. 2000 Dec; 36(6): 73-75.

[3] Wu DX, Lan TP, Liu QY. Research status and prospect of soil structure. Journal of Hefei University of Technology Natural Science Edition. 2009 Dec; 32(12): 1904-1910.

[4] Huang XH, Wu ZH. Study on engineering characteristics of calcareous nodular clay in a power plant. Electric Power Survey and Design. 2010 Feb; (1): 16-19.

[5] Lan TP. Large scale direct shear test of calcareous nodule soil in Huaibei Plain. Hefei University of Technology; 2012 Apr.

[6] Xiong YH, Hu B. Strength test and foundation bearing capacity evaluation of calcareous nodule soil West-China. West-China Exploration Engineering. 2010 Feb; 22(2): 3-5. 